\section{Radioiodine Treatment Triggers Security Alarms: Case Report and Review of Literature}

TO THE EDITOR: Since the September 11 attacks, security procedures have been strengthened in order to identify terrorist threats. An increasing number of sensitive radiation detectors have been installed in airports, public transportation facilities, and other ports of entry, in an effort to neutralize smuggling and trading of nuclear weapons, radiation dispersal bombs, and other weapons of mass destruction. However, the number of patients receiving radioactive substances for diagnostic or therapeutic purposes has also been increasing.

Despite the fact that this situation is becoming more common, few cases have been described in the literature. As reported, security alarms can be triggered by patients who have received radioactive tracers for diagnostic (1-3) or therapeutic (4-7) purposes. Also, other cases have been reported by the media (8). Interestingly enough, passive tracer incorporation (caused by close contact with patients receiving radioactive substances) may also trigger radiation alarms (9). The likelihood that a physician will face this situation increases each day. However, despite the fact that the Society of Nuclear Medicine (10) and the United States Nuclear Regulatory Commission (7) have published letters of guidance addressing this issue, many physicians are still unaware of it. As a result, many patients who receive diagnostic or therapeutic radioactive substances may now face hassle and embarrassment because of security protocols.

Here, we report another case of radiation detectors being triggered by a patient treated with ${ }^{131} \mathrm{I}$. A 60 -y-old woman received $1,110 \mathrm{MBq}$ of ${ }^{131} \mathrm{I}$ for the treatment of a $15 \mathrm{-g}$ nontoxic multinodular goiter. She was living in an iodine-sufficient region and had no previous history of other medical illnesses or current use of medications. Also, she was not put on an iodine-restricted diet before the treatment. She was advised to avoid public transportation and close physical contact with others for $2 \mathrm{wk}$. After $24 \mathrm{~d}$, she took a flight from Brazil to Miami International Airport, where she set off the radiation alarm of a portable radiation detector carried by the U.S. customs officials. She was taken to a separate room, where, after a thorough investigation, she remembered having been treated with radioiodine. The patient was then allowed to enter the United States. Radiation dosimetry was performed on her $38 \mathrm{~d}$ after she had received the ${ }^{131} \mathrm{I}$, and the reading was considerably low $(30 \mu \mathrm{Sv} / \mathrm{h})$. She returned from Miami to Brazil on that day, and no alarms were triggered at that time.

We would like to address the fact that sensitive radiation detectors are now being used in an increasing number of public facilities, as well as during large public events. To our knowledge, only 10 similar cases (including ours) have been reported in the medical literature, and cases such as this are most likely underreported. Most of these cases happened a few days after the tracer had been given, but because of the high sensitivity of radiation detectors, alarms can be triggered many weeks after tracer administration, depending on the radiotracer that is administered (up to $95 \mathrm{~d}$ for ${ }^{131} \mathrm{I}$ and up to $30 \mathrm{~d}$ for ${ }^{201} \mathrm{Tl}(6)$ ).

We suggest that all patients, regardless of the total activity of radiation administered, should indefinitely carry medical documentation reporting treatments or diagnostic procedures with radioactive substances. Moreover, physicians should be encouraged to keep records and report all cases of alarm triggering due to radioactive substances. Such measures would increase awareness of this situation within the medical community.

\section{REFERENCES}

1. Toltzis RJ, Morton DJ, Gerson MC. Problems on Pennsylvania Avenue. N Engl J Med. 1986;315:836-837.

2. Levin ME, Fischer KC. Thallium stress tests and bank vaults [letter]. $N$ Engl J Med. 1988;319:587.

3. Iqbal MB, Sharma R, Underwood SR, Kaddoura S. Radioisotopes and airport security. Lancet. 2005;366:342.

4. Buettner C, Surks MI. Police detainment of a patient following treatment with radioactive iodine [letter]. JAMA. 2002;288:2687.

5. Sinzinger H, Aiginger P, Neumann I, Havlik E. Radiation alarm at an airport after radioiodine therapy. Nucl Med Commun. 2005;26:67-68.

6. Gangopadhyay KK, Sundram F, De P. Triggering radiation alarms after radioiodine treatment. BMJ. 2006;333:293-294.

7. The U.S. Nuclear Regulatory Commission Office of Nuclear Material Safety and Safeguards. NRC information notice 2003-22: heightened awareness for patients containing detectable amounts of radiation from medical administrations. Available at: http://www.nrc.gov/reading-rm/doc-collections/gen-comm/infonotices/2003/in200322.pdf. Accessed November 19, 2007.

8. Reuters. Radioactive Patients. Available at: http://www.reuters.com/article/ health-SP-A/idUSN2633076820070209. Accessed November 19. 2007.

9. Sinzinger H, Aiginger P, Neumann I, Havlik E. Passive incorporation of radioisotopes and airport security [letter]. Nucl Med Commun. 2007;28:423.

10. SNM press release. Nuclear Medicine Patients: No-Alarm Holiday Travel Tips. Available at: http://interactive.snm.org/index.cfm?PageID $=5660 \&$ RPID $=627$. Accessed November 19, 2007.
Gilberto J. Paz-Filho João V. Busnello Julio Licinio University of Miami Miami, Florida

Flávio Zelmanovitz Hospital de Clínicas de Porto Alegre Porto Alegre, Brazil 